J. Phys. Chem. Solids, 41 [6] 647-52 (1979).

${ }^{24}$ E. M. Logothetis and J. K. Park, "Charge Transport and Lattice Defects in CoO," Solid State Commin. 43 [7] 543-46 (1982)

${ }^{25}$ H. - C. Chen and T. O. Mason, "Thermoelectric Study of Cobaltous Oxide Defect Structure," J. Am. Ceram. Soc., 64 [10] C-130-C-133 (1981)

${ }^{26} \mathrm{~J}$. Nowatny, I Sikora, and M. Rekas, "Defect Structure and Electrical Properties of Undoped and Cr-Doped CoO," J. Electrochem. Soc., 131 [1] 94-100 (1984).

${ }^{27}$ J. J. Stiglich, D. H. Whitmore, and J. B. Cohen, "Defect Structure of NiO-CoO Solid Solutions," J. Am. Ceram. Soc., 56 [4] 211-13 (1972).

${ }^{28} \mathrm{P}$. Kofstad, "Diffusional Transport in MnO," Solid State Ionics, 12 [2] 101-1] (1984).

${ }^{29}$ D. A. O. Hope, A. K. Cheetham, and G. J. Long, “A Neutron Diffraction, Mag netic Susceptibility, and Mössbauer-Effect Study of the $\left(\mathrm{Mn}_{x} \mathrm{Fe}_{1-x}\right)_{y} \mathrm{O}$ Solid Solutions," Inorg. Chem., 21 [7] 2804-809 (1982)

${ }^{30}$ M. S. Jagadeesh and M.S. Seehra, "Study of Some Magnetic Properties of a Mixed Phase $\left(\mathrm{Mn}_{3} \mathrm{O}_{4}\right)$ in MnO Crystals," Phys. Rev., B21 [7] 2897-904 (1980)

C. Carel, J. Arabski, J.-R. Gavarri, St. Jasienska, and J. Janowski, "Thermodynamic Properties, Magnetic Transition, Transport Phenomena During Quenching, Brittleness and Morphology of Manganosite"; Ind Round Table Meeting on Fe-Mn-O, Kuzubrick, Poland, September, 1983.

${ }_{32} \mathrm{R}$. Tetot and P. Gerdanian, "Theoretical Considerations Regarding the Defect Structure of $\mathrm{M}_{1-x} \mathrm{O}$ Cubic Oxides for Small Departures From Stoichiometry," J. Phys. Chem. Solids, 46 [7] 869-79 (1985)

${ }^{33}$ C. R. A. Catlow, B. Fender, and D. G. Muxworthy, "Defect Interactions and
Order-Disorder in Transition Metal Oxides," J. Phys. (Orsay, Fr.), 38 [C7] [12] $67-71(1977)$

${ }^{34}$ A. B. Anderson, R. W. Grimes, and A. H. Heuer, "Defect Clusters in Wustite, $\mathrm{Fe}_{1-\mathrm{X}} \mathrm{O}$," J. Solid State Chem., 55 [3] 353-61 (1984)

${ }^{35}$ A. B. Anderson, "Derivation of the Extended Huickel Method with Corrections One Electron Molecular Orbital Theory for Energy Level and Structure Deter minations," J. Chem. Phys., 62 [3] 1187-88 (1975).

${ }^{36}$ A. B. Anderson, "Derivation of and Comments on Bonaccorsi-Scrocco-Tomasi Potentials for Electrophilic Additions," J. Chem. Phys., 60 [6] 2477-709 (1974)

"M.S. Seehra and G. Srinivason, "Magnetic Studies of Non-Stoichiometric Fe and Evidence for Magnetic Defect Clusters," J. Phys. C. 17 [5] 883-92 (1984)

${ }^{38}$ D. G. Muxworthy, "The Defect Properties of Transition Metal Oxides," U.K.At. Energy Res. Establ., Rep., T.P. 667 (1978)
D.

${ }^{39}$ J. W. Richardson, W. C. Nieupoort, R. R. Powell, and W. F. Edgell, "Approximate Radial Functions for First-Row Transition Metal Atoms and Ions. I Inner-Shell, $3 d$ and 4s Atomic Orbitals," J. Chem. Phys., 36 [4] 1057-61 (1962) ${ }^{40}$ W. Lotz, "Electron Binding Energies in Free Atoms," J. Opt. Soc. Am., 60 [2] $206-10(1970)$.

${ }^{41}$ C. E. Moore, "Atomic Energy Levels," Nat. Stand. Ref. Data Ser. (U.S., Nat. Bur. Stand.), 35 (1971)

${ }^{42}$ E. Clementi and D. L. Raimondi, "Atomic Screening Constants From SCF Functions,"J. Chem. Phys., 38 [11] 2686-89 (1963).

${ }^{43}$ L. Pauling, The Nature of the Chemical Bond, 3rd ed. Cornell University Press, Ithaca, NY, 1960 .

\title{
Redistribution of Aluminum Ions During Processing of Sialon Ceramics
}

\author{
D. A. BONNELL, ${ }^{*, *, \dagger}$ M. RÜHLE, ${ }^{*, \dagger}$ and T.-Y. TIEN ${ }^{\star, *}$
}

Department of Materials and Metallurgical Engineering, The University of Michigan, Ann Arbor, Michigan 48109, and Max-Planck-Institut für Metallforschung, Institut für Werktoffwissenschaften, 7000 Stuttgart 1, Federal Republic of Germany

\begin{abstract}
Precise determinations of the variation in Al concentration in $\beta$-sialon grains of the garnet and cordierite sialon systems were made by means of quantitative energy-dispersive $X$-ray analysis in an analytical electron microscope. Different signs of the concentration gradients in the grain indicate differences in secondary crystallization mechanisms, while Al distributions with respect to grain size indicate a changing glass-silicon nitride compatability during crystallization. The technique was also applied to the glassy grain-boundary phase allowing the determination of the glass-forming region of the cordierite-sialon system. A detailed evaluation of errors in analytical transmission electron microscopy (AEM) is described.
\end{abstract}

\section{Introduction}

G RAIN-BOUNDARY reactions involving secondary phases often dictate the mechanisms controlling the mechanical properties of advanced ceramics. In silicon nitride ceramics, for example, the oxide additions required by densification become a glassy second phase on cooling from sintering temperatures. ${ }^{1}$ This glassy phase degrades the mechanical properties, particularly at high temperatures. If the composition of the second phase is such that it can crystallize on subsequent annealing, high-temperature mechanical properties are significantly improved. ${ }^{2}$

Received September 30, 1985; revised copy received March 13, 1986; approved March 17, 1986

Supported by the U.S. Department of Energy, Office of Basic Energy Science, Division of Materials Science, under Contract No. DE-FG02-84-ER45069 at the University of Michigan. At the time that the microscopy was done, D. A. B. was at the Max-Planck Institute under the support of a Fulbright fellowship.

*Member, the American Ceramic Society.

*The University of Michigan.

${ }^{\dagger}$ Max-Planck-Institut für Metallforschung.
In an attempt to characterize the crystallization of this second phase, several investigators have examined the crystallization of oxynitride glasses in the bulk state. ${ }^{3,4}$ Similar studies in the silicon nitride material are much more difficult because the glass phase is only a minor component $(<15$ vol\%). However, in some cases, specifically non-Al-containing materials, glass phase separation has been observed before nucleation in the grain-boundary glass phase. $^{5}$

This paper reports a study in which the crystallization mechanisms are identified in two glass-containing silicon nitride materials. This type of investigation requires the accurate measurement of light element content as a function of grain size, as well as a technique with high spatial resolution to determine composition profiles within individual grains. Knowledge of the equilibrium phase relations is also necessary.

Analytical transmission electron microscopy (AEM) can be a valuable tool in characterizing such reactions; however, serious limitations exist, particularly in the analyses of low-energy peaks. Frequently, the errors involved in such measurements degrade the certainty to the extent that small changes in composition cannot be reliably distinguished.

This paper explicitly discusses the possible sources of error encountered in the quantitative measurement of absolute and relative concentrations of low-atomic-number elements $(12<n<14)$. The standard methods of reducing such errors are described and a statistical approach that significantly increases the reliability of the results is demonstrated. Implications of the composition distributions and gradients are then discussed in terms of Al mobility during processing and nucleation mechanisms. Finally, the method is applied to phase diagram determination and the glass-forming region of the cordierite-sialon system on cooling from $1700^{\circ} \mathrm{C}$ is presented. 
Table I. Sample Preparation

\begin{tabular}{|c|c|c|c|c|c|c|c|c|}
\hline & \multicolumn{6}{|c|}{ Composition (\%) } & \multirow[b]{2}{*}{ Heat treatment } & \multirow[b]{2}{*}{ Phases } \\
\hline & $\mathrm{Si}_{3} \mathrm{~N}_{4} *$ & $\mathrm{Al}_{2} \mathrm{O}_{3}^{\dagger}$ & $\operatorname{AlN}^{\ddagger}$ & $\mathrm{SiO}_{2}{ }^{8}$ & $\mathrm{MgO}^{\pi}$ & $\mathrm{Y}_{2} \mathrm{O}_{3}{ }^{* *}$ & & \\
\hline$\beta_{5}-20 \mathrm{HP}$ & 75.53 & 7.60 & 4.12 & 10.27 & 2.76 & & & \\
\hline$\beta_{5}-20 \mathrm{ANN}$ & 75.53 & 7.60 & 4.12 & 10.27 & 2.76 & & & $\beta$, glass \\
\hline$\beta_{10^{-}} 10 \mathrm{HP}$ & 78.59 & 8.67 & 6.09 & 5.24 & 1.41 & & $97 \mathrm{~h}, 1000^{\circ} \mathrm{C}$ & $\beta$, cordierite \\
\hline$\beta_{10^{-1}} 10 \mathrm{ANN}$ & 78.59 & 8.67 & 6.09 & 5.24 & 1.41 & & & $\beta$, glass \\
\hline$\beta_{30}-10 \mathrm{HP}$ & 57.20 & 24.77 & 11.50 & 5.14 & 1.38 & & $97 \mathrm{~h}, 1000^{\circ} \mathrm{C}$ & $\beta$, cordierite \\
\hline$\beta_{10}-10(\mathrm{Y}) \mathrm{HP}$ & 78.87 & 9.53 & 6.10 & & & 5.85 & & $\beta$, glass \\
\hline$\beta_{10}-10(\mathrm{Y}) \mathrm{ANN}$ & 78.87 & 9.53 & 6.10 & & & 5.85 & $57 \mathrm{~h}, 1250^{\circ} \mathrm{C}$ & $\beta$, garnet \\
\hline
\end{tabular}

${ }^{*}$ Stark LC12, Hermann C. Stark, Inc., New York, NY. ${ }^{\dagger}$ Alcoa A 16, Aluminum Co. of America, Pittsburgh, PA. ${ }^{\ddagger}$ Stark. ${ }^{8}$ Salicic acid calcined 5 h, $1000^{\circ} \mathrm{C}$, Mallinckrodt, Inc., St. Louis, $\mathrm{MO} .{ }^{\mathrm{MgCO}} \mathrm{Mg}_{3}$ calcined $1 \mathrm{~h}, 1000^{\circ} \mathrm{C}$, Mallinckrodt, Inc. ** Malycorporation 5600.

\section{Experimental Procedure}

In order to better understand the chemical changes occurring during the processing of silicon nitride ceramics, Al distributions and gradients were analyzed in two systems, cordierite-sialon. Sialon here refers to an Al-O-substituted $\beta$-silicon nitride according to the formula $\mathrm{Si}_{6-x} \mathrm{Al}_{x} \mathrm{O}_{x} \mathrm{~N}_{8-x}$. The ratios of the oxide additives were adjusted such that cordierite $\left(2 \mathrm{MgO} \cdot 2 \mathrm{Al}_{2} \mathrm{O}_{3} \cdot 5 \mathrm{SiO}_{2}\right)$ or garnet $\left(\mathrm{Y}_{3} \mathrm{Al}_{5} \mathrm{O}_{12}\right)$ and sialon were the only crystalline phases present after annealing. To achieve such composition control, it is necessary to compensate for the oxygen impurity that occurs as a surface layer of $\mathrm{SiO}_{2}$ on the silicon nitride powder as well as the alumina pick up from the milling process.

The starting powders were $\mathrm{Al}_{2} \mathrm{O}_{3}, \mathrm{AIN}, \mathrm{SiO}_{2}, \mathrm{Si}_{3} \mathrm{~N}_{4}$, and $\mathrm{MgCO}_{3}$ or $\mathrm{Y}_{2} \mathrm{O}_{3}$ and were combined in the proportions listed in Table I. Powders were milled in anhydrous methanol for $2 \mathrm{~h}$, dried, and finally hot-pressed in boron nitride coated graphite dies for $2 \mathrm{~h}$ at $1740^{\circ} \mathrm{C}$ under $27 \mathrm{MPa}$ in flowing nitrogen. Annealing was done in a $\mathrm{Pt}$ wound vertical tube furnace with a nitrogen flow of $1 \mathrm{~L} / \mathrm{min}$. Conditions for maximum crystallization were experimentally determined and are presented in Table I. Phases present after each processing step were determined by X-ray diffractometry.

Thin 3-mm disks were cut with a diamond saw from the sintered specimen, mechanically ground to $100 \mu \mathrm{m}$, and dimpled to $60 \mu \mathrm{m}$. Foils were then ion beam thinned with $6-\mathrm{kV}$ argon ions at an incidence angle of $12^{\circ}$. A thin layer of carbon was evaporated onto the foils to avoid charging. Analytical microscopy was done with an instrument ${ }^{\ddagger}$ operated at $200 \mathrm{keV}$. The instrument was equipped with a $\mathrm{Si}(\mathrm{Li}) \mathrm{X}$-ray detector at a $72^{\circ}$ takeoff angle, signal processing, and computer analysis facilities. ${ }^{\S}$

\section{Analytical Transmission Electron Microscopy (AEM)}

In order to reliably distinguish small differences in relative or absolute composition, the following sources of error, which will be described in detail below, must be accounted for and if possible reduced: (1) error in $K$ factor determination (10\%), (2) absorption error $(3 \%)$, (3) phase overlap error $(x),(4)$ fit error $(10 \%)$, and (5) statistical error $(10 \%)$.

The total uncertainty in the measurement is then a sum of all possible errors, shown in parentheses above. In the analysis of small concentrations of low-atomic-number elements which typically have low count rates, the fit error and statistical error can be quite large. When error bars and confidence levels are not reported, the significance of the results can be in question because errors of this magnitude must be assumed. This magnitude of uncertainty is clearly unacceptable for quantitative analysis and efforts are made to reduce it.

(1) Errors inherent in the $K$ factor can be ignored when considering only relative concentration differences. When absolute concentrations are required, this error must be quantified. In this study, the phase diagram was determined using calculated $K$ val-

Model 200CX, JEOL, Peabody, MA

Model TN 2000, Tracor Northern, Middleton, WI. ues which can have a relative error of $+15 \%$. ' However, microscope calibration studies on the instrument used show the error to be at least one-half of that predicted.

(2) The thin-foil criterion is here defined as the thickness under which $<3 \%$ difference can be produced by the effects of X-ray absorption in the foil ${ }^{7}$ This results in a thickness limit of $200 \mathrm{~nm}$ for all species in the sialon and $150 \mathrm{~nm}$ for all species in the glass phase. However, errors in relative concentration will not occur by $\mathrm{X}$-ray absorbtion unless the X-rays are absorbed at different rates. For example, if $10 \%$ of the $\mathrm{X}$-rays produced by $\mathrm{Si}$ and $\mathrm{Al}$ atoms are absorbed, the intensity ratio, and thus the concentration ratio, remain unchanged. Because the elements analyzed in this study have similar atomic numbers, the absorption rates will be similar. Therefore, the concentration error that can result from absorption is much less than $3 \%$ and absorption corrections, along with their inherent errors, are not necessary.

(3) "Phase overlap error" occurs when X-rays generated from a secondary phase or a different grain are detected during the analyses of a grain. This will happen, at an inclined grain boundary when a second-phase pocket is hidden under the grain, or when beam broadening due to inelastic scattering or contamination occurs near a grain boundary. The overlap error results in an increase in the $\mathrm{Al}: \mathrm{Si}$ ratio in the system examined here. To avoid this, grains were chosen that were hexagonal, indicating that they were transversally sectioned and not inclined to the foil. All grains analyzed were at least as wide as the foil thickness and were therefore assumed to extend through the foil. Extensive tilting was routinely done before analysis to avoid overlap conditions.

(4) "Fit error" arises from the method used to determine the number of counts under the peaks. In a quantificatioin routine whereby reference peaks are matched to the peaks from the spectra, the error results from statistical fluctuations in the reference and unknown peaks, errors inherent in the background subtraction routine, differences in the peak window boundaries (an operatorspecified parameter), differences in the effects of peak overlap deconvolution, and error caused by imperfect matching to the reference peaks (usually quantified by a $\chi^{2}$ factor). The first type can be reduced by choosing a reference peak with a much higher intensity than unknown peak, thereby decreasing the relative effect of its statistical fluctuation. The error caused by background subtraction has a stronger effect than the first, particularly for lowatomic-number, low-intensity peaks, favoring a higher Si content in this system. This error can be reduced by standard methods of increasing the peak-to-background ratio. ${ }^{7}$ The error from peak matching will obviously be reduced by matching every unknown peak with a new reference peak, but this is highly impractical. The individual contributions of the errors in quantification will vary with each analysis, further decreasing the reliability. These errors will be accounted for in multiple-spectra analysis as discussed later.

(5) In silicon nitride ceramics, statistical error can be the largest source of inaccuracy. Primarily low-atomic-number elements are analyzed, some of which are present in very small concentrations. This gives low count rates in minor peaks, while the major peak count rate is at a maximum. Count times cannot exceed 10 min because of contamination and specimen drift. As shown 
Table II. Comparison of Singleand Multiple-Spectra Analyses

\begin{tabular}{|c|c|c|c|c|c|}
\hline Sample & Size* & $\mathrm{Al}: \mathrm{Si}$ & Absolute error ${ }^{\dagger}$ & $\begin{array}{l}\text { No. of } \\
\text { spectra }\end{array}$ & $\begin{array}{l}\text { Standard } \\
\text { deviation }\end{array}$ \\
\hline spectra A & $\mathbf{s}$ & 0.020 & \pm 0.010 & 1 & \\
\hline spectra B & 1 & 0.032 & \pm 0.005 & 1 & \\
\hline spectra C & s & 0.073 & \pm 0.010 & 1 & \\
\hline spectra D & l & 0.085 & \pm 0.008 & 1 & \\
\hline Sample & Size* & $\% \mathrm{Al}$ & Absolute error ${ }^{*}$ & $\begin{array}{l}\text { No. of } \\
\text { spectra }\end{array}$ & $\begin{array}{l}\text { Standard } \\
\text { deviation }\end{array}$ \\
\hline$\beta_{5}-20 \mathrm{HP}$ & s & 4.49 & \pm 0.74 & 8 & 0.89 \\
\hline$\beta_{5}-20 \mathrm{HP}$ & $\mathrm{m}$ & 6.18 & \pm 0.94 & 15 & 1.70 \\
\hline$\beta_{5}-20 \mathrm{HP}$ & 1 & 7.26 & \pm 1.49 & 14 & 2.60 \\
\hline$\beta_{5}-20$ ANN & $\mathrm{s}$ & 4.25 & \pm 0.57 & 7 & 0.62 \\
\hline$\beta_{5}-20$ ANN & $\mathrm{m}$ & 4.57 & \pm 1.07 & 12 & 1.68 \\
\hline$\beta_{\mathrm{s}}-20 \mathrm{ANN}$ & 1 & 4.67 & \pm 0.72 & 15 & 1.30 \\
\hline$\beta_{10}-10 \mathrm{HP}$ & $\mathrm{s}$ & 8.01 & \pm 1.62 & 12 & 2.56 \\
\hline$\beta_{10}-10 \mathrm{HP}$ & 1 & 9.77 & \pm 2.80 & 10 & 3.92 \\
\hline$\beta_{10}-10 \mathrm{ANN}$ & $\mathrm{s}$ & 9.48 & \pm 0.70 & 7 & 0.76 \\
\hline$\beta_{10}-10$ ANN & 1 & 9.99 & \pm 2.86 & 6 & 2.73 \\
\hline Sample & Species & $\%$ & Absolute error ${ }^{+}$ & $\begin{array}{l}\text { No. of } \\
\text { spectra }\end{array}$ & $\begin{array}{l}\text { Standard } \\
\text { deviation }\end{array}$ \\
\hline \multirow{3}{*}{$\begin{array}{c}\beta_{5}-20 \\
\text { glass }\end{array}$} & $\mathrm{Mg}$ & 11.60 & \pm 0.63 & 17 & 1.48 \\
\hline & Al & 22.85 & \pm 1.08 & 17 & 2.54 \\
\hline & $\mathrm{Si}$ & 65.54 & \pm 1.42 & 17 & 3.34 \\
\hline \multirow{3}{*}{$\begin{array}{c}\beta_{10^{-}} 10 \\
\text { glass }\end{array}$} & $\mathrm{Mg}$ & 10.03 & \pm 1.31 & 15 & 2.88 \\
\hline & $\mathrm{Al}$ & 20.42 & \pm 1.51 & 15 & 3.32 \\
\hline & $\mathrm{Si}$ & 68.58 & \pm 2.17 & 15 & 4.79 \\
\hline \multirow[t]{3}{*}{$\beta_{30}-10$} & $\mathrm{Mg}$ & 12.74 & \pm 2.33 & 5 & 1.54 \\
\hline & $\mathrm{Al}$ & 23.23 & \pm 2.20 & 5 & 1.47 \\
\hline & $\mathrm{Si}$ & 64.00 & \pm 4.01 & 5 & 2.67 \\
\hline
\end{tabular}

${ }^{*} \mathrm{~s}=$ grains smailer than $0.3-\mu \mathrm{m}$ diameter. $\mathrm{m}=$ grains between $0.3-$ and $1-\mu \mathrm{m}$ diameter. $1=$ grains larger than $1-\mu \mathrm{m}$ diameter. ${ }^{\dagger}$ At $98 \%$ confidence

later, this error is also effectively reduced in multiple-spectra analysis.

For the determination of the relative concentration of $\mathrm{Al}$ in sialon, we need not consider the $K$ factor error. We can neglect the absorption error and avoid the overlap error. Therefore, assuming a peak intensity of 2000 counts (typical of the $\mathrm{Al}$ peak in sialon 100 -nm thick, 200 -s counting time with $200-\mathrm{keV}$ electrons), the relative error is reduced to

$$
\begin{aligned}
& \text { relative error }=e_{f}+3(N / \sqrt{N}) \\
& 20.5 \%=13.8 \%+6.7 \%
\end{aligned}
$$

where $e_{f}$ is the fit error, which is the sum of uncertainty in background subtraction and uncertainty in peak matching and $3(N / \sqrt{N})$ is the statistical counting error.

This degree of error is still unacceptably high and cannot be further reduced in single-spectrum analysis. However, multiplespectra analyses allow substantial improvement. With this technique, 10 to 20 spectra of similar grains are collected and statistically analyzed via the student $t$ treatment. The appropriate formulas are presented in the Appendix. In this way the error can be reduced by a factor of 2 and a much higher sensitivity is achieved.

\section{Results}

The results of the X-ray analysis are presented in Table II, along with the absolute error associated with each measurement and the standard deviation of the multiple-spectra analyses. Spectra A and $\mathrm{B}$ were determined in an area where the sample thickness was $<100 \mathrm{~nm}$, while $C$ and $D$ came from an area of thickness

In practice, this is taken to be the uncertainty in the background, an approximation that holds when the peak-to-background ratio is high but fails when it is not.

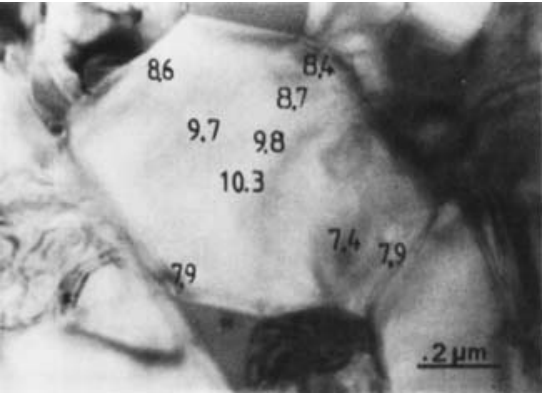

Fig. 1. A TEM micrograph of a $\beta$-sialon grain showing the variation in $\mathrm{Al}$ content in a hotpressed specimen containing $10 \mathrm{wt} \%$ glass phase. The Al content is clearly lower at the grain edges than at the grain center.

$\approx 200 \mathrm{~nm}$. A comparison of these two sets of data illustrates the effect of sample thickness on count rate and thus counting statistics. In spite of the improved sensitivity of this method, a minimum peak height is required to reduce counting statistic error. The statistical error in spectra A and B is so large that differences in $\mathrm{Al}: \mathrm{Si}$ ratio of $<60 \%$ will not be distinguished. The uncertainty remains high in spite of the application of student $t$ statistics to multiple spectra.

In choosing specimen areas with thicknesses between 100 and $200 \mathrm{~nm}$, as in spectra C and D, peak intensities are high enough that counting statistics are reduced to a level where small differences in $\mathrm{Al}$ : $\mathrm{Si}$ ratio should be distinguishable. Note, however, that even in this case, it is not possible to measure a difference in the $\mathrm{Al}$ content between large and small grains when only single spectra are compared. Spectra C and D, from small and large grains respectively, indicate a trend of increasing $\mathrm{Al}$ content with size. The error, which primarily includes counting statistics, does not allow this interpretation. However, when multiple spectra are analyzed via standard student $t$ treatment, the errors are reduced to the extent that this trend can be reliably distinguished (see Table II). Not only are small differences in $\mathrm{Al}: \mathrm{Si}$ obvious, but all other sources of error are included as well, specifically phase overlap error and all fit errors. The omission of these error sources could invalidate the results. It should be pointed out that this technique is not new. It is, in fact, commonly used to reduce the error in measured $K$ factor determinations. ${ }^{7}$ It does not seem, however, to be used in routine compositional analyses.

Multiple-spectra analyses of the Al content, as measured in the center of sialon grains, are listed as a function of grain size and processing. In the hot-pressed state, the small grains have a lower Al content $(4.49 \% \pm 0.74 \%)$ than the large grains $(7.26 \% \pm$ $1.49 \%$ ). During annealing, the $\mathrm{Al}$ redistributes and the $\mathrm{Al}$ concentration is then homogeneous with respect to grain size

This same multiple-spectra approach cannot be applied to the measurement of compositional gradients in the small grains typical of ceramic materials. Because of grain size limitations, repeated analyses at each point in the profile are not possible. In this case, the quantitative determination of compositional differences is limited by the uncertainty of single spectra. However, here trends can be verified by the comparison of gradients in many grains.

Composition profiles of 5 to 10 grains were measured in each of six samples, three with cordierite composition glass and three with garnet composition glass phase. Figure 1 illustrates the results of one such analysis. Figure 2 schematically compares the gradients that occur when the grains were completely surrounded by glass. The high spatial resolution of this technique allowed the determination of more complex gradients which arise in cases where the grains are not entirely surrounded by glass, as shown in Fig. 3. The composition analysis of the glass phase in several "as-hot-pressed" samples (see Table II) delineates the glass-forming region of the cordierite-sialon system as shown in Figs. $4(A)$ and $(B)$. The glass- 
Cordierite-SIALN
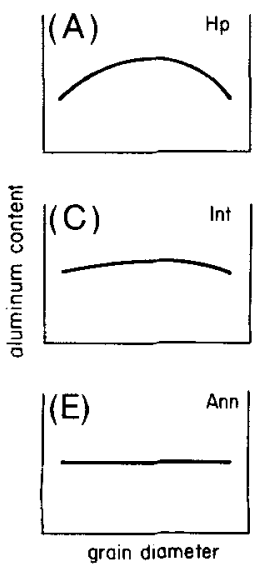

Gornet-SIAION
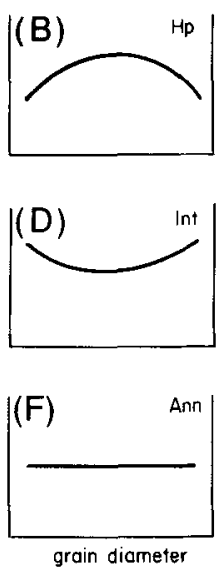

Fig. 2. Schematic representation of the composition gradients that occur in sialon grains is depicted as a function of glass phase and processing. First, the gradients in the hot-pressed specimens $(A$ and $B)$, then those in specimens annealed for intermediate time periods $(C$ and $D$ ), and finally those in the long time annealed samples are shown $(E$ and $F$ ). The striking feature is the gradient reversal that occurs in the gamet-sialon series $(B, D$, and $F)$.

forming region on the cordierite- $\mathrm{Si}_{3} \mathrm{~N}_{4}-\beta_{30}$ plane which was determined in this investigation is consistent with the projections of the glass-forming regions of other planes in the system. ${ }^{8}$ The large standard deviation in these measurements reflects the degree of inhomogeneity in the glass phase.

\section{Discussion}

Understanding the nucleation processes in the grain-boundary glass phase will be important to the optimization of silicon nitride materials. It is through the control of these processes via heattreatment cycles that the final microstructure is controlled. In this way the room-temperature, as well as high-temperature mechanical properties can be tailored. Following the chemical changes that occur during processing leads to an understanding of nucleation mechanisms. As previously mentioned, the Al content of the small grains in hot-pressed silicon nitride is lower than that of the large grains. This is evident in samples with 10 as well as $20 \mathrm{wt} \%$ glass phase.

The compositional inhomogeneity with respect to grain size in the hot-pressed samples could be explained in two ways. It is probable that the AI solubility in the silicon nitride decreases with decreasing temperature because the substitution of $\mathrm{Al}-\mathrm{O}$ pairs in the silicon nitride structure causes a lattice expansion. ${ }^{9}$ The smaller grains, with a higher surface-to-volume ratio, equilibrate faster than the larger grains as the sample cools from hot-pressing temperatures. The effectiveness of the glass phase in accommodating the $\mathrm{Al}$ can be seen in the fact that the standard deviation of the $\mathrm{Al}$ content in samples with only $10 \%$ glass phase is usually larger than in the samples with $20 \%$.

Alternatively, the equilibrium concentration of the phases could be changing during the $\beta$ crystallization process. Phase relations indicate that the initial glass composition, which is $\mathrm{Al}$ rich, will be compatible with a highly substituted silicon nitride. ${ }^{10} \mathrm{As} \mathrm{Al}$ continues to be absorbed into the silicon nitride, the glass becomes less rich in $\mathrm{Al}$ and will be in local equilibrium with silicon nitride of a lower Al content. Assuming that the largest grains were the first to nucleate, they should have the highest $\mathrm{Al}$ content.

The first explanation is more likely when the $\mathrm{Al}$ mobility is high, while the second applies to the case of low Al mobility. The Al mobility depends not only on the driving force due to decreasing solubility, but also on the diffusivity of $\mathrm{Al}$ in $\mathrm{Si}_{3} \mathrm{~N}_{4}$, as well as the ability of the second phase to accommodate the rejected Al. The extremely low diffusivities of $\mathrm{Al}$ in silicon nitride suggest that the second explanation applies.

The same argument can be made when considering the Al gradients in the hot-pressed samples. As the crystal grows, the equilibrium concentration of $\mathrm{Al}$ in the silicon nitride decreases. The last $\beta$ to crystallize, at the grain edges, contains the least Al. The concentration profile should be such that the $\mathrm{Al}$ content decreases from the center of the grain toward the edges. This is, in fact, seen as illustrated schematically in Figs. $2(A)$ and $(B)$. The gradients are present in large $\mathrm{Si}_{3} \mathrm{~N}_{4}$ grains, regardless of the composition of the glass phase.

In the samples annealed for long times at $1000^{\circ} \mathrm{C}$, the gradients are not observed (Figs. $2(E)$ and $(F)$ ). As mentioned above, the lower Al diffusivity and crystallinity of the second phase would reduce the $\mathrm{Al}$ mobility to the extent that the gradients are not produced.

Interesting differences between the two systems are seen on examining samples between the two extremes, i.e., those annealed for short times. In the garnet-sialon samples, a gradient forms with increasing Al towards the edges of the grains (Fig. 2(D)) a reversal of the gradient in the hot-pressed condition. This indicates that secondary silicon nitride, with a higher $\mathrm{Al}$ content, is precipitating from the glass phase on existing $\beta$ grains.

In contrast, this type of gradient is not observed in the cordieritesialon system (Fig. $1(C)$ ) even though phase relations predict a higher Al content in secondary $\beta$ in this system as well. ${ }^{11}$ Therefore, the secondary silicon nitride is not precipitating on existing $\beta$ grains. Differences of the structure in the second-phase pockets further illustrate the differences in the nucleation sites of the sec-

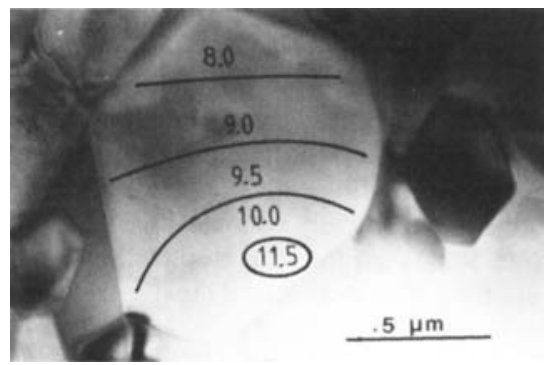

Fig. 3. TEM micrograph of a $\beta$-grain showing the Al profile mapping possible with such a high spatial resolution analytical technique.
(A)

Cordierite
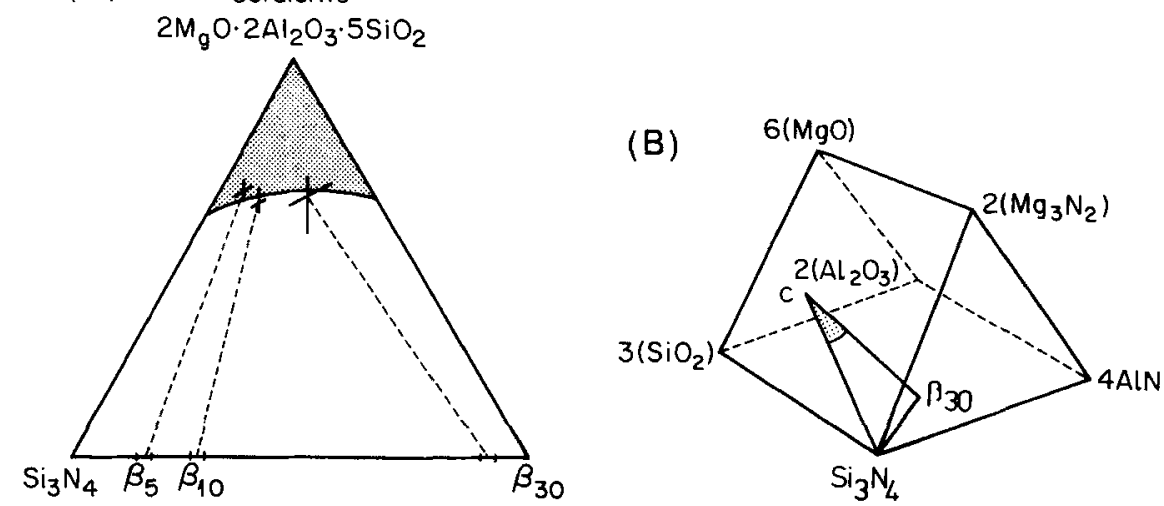

Fig. 4. Glass-forming region of the cordierite-sialon system at $1700^{\circ} \mathrm{C}$ is normalized to weight percent as a ternary diagram $(A)$ and to equivalent percent in a six-component representation $(B)$. 


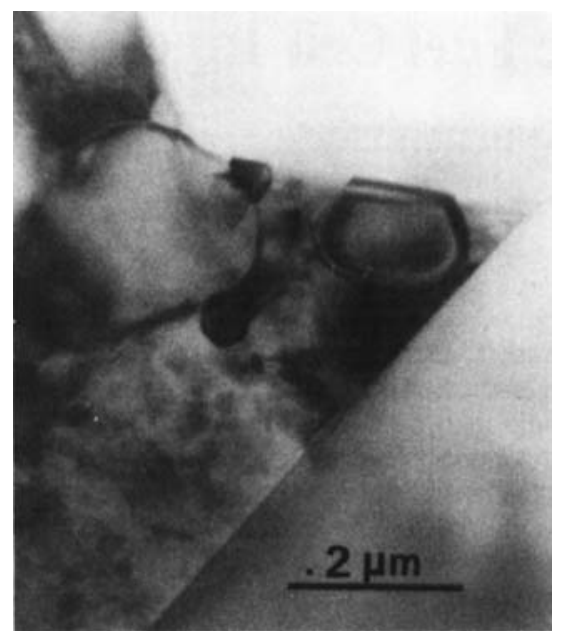

Fig. 5. Silicon nitride grains in the secondphase pockets of the cordierite-sialon annealed samples, such as is illustrated by this TEM micrograph, are smaller than those seen in the hot-pressed materials.

ondary silicon nitride. The structure typical of a second-phase pocket in cordierite-sialon is shown in Fig. 5. Very small silicon nitride grains are found in these pockets, along with the crystallized cordierite. Although it is not possible to reliably measure the $\mathrm{Al}$ content of these grains because of significant phase overlap conditions, it can be inferred from their size that they are secondary crystals. These grains are always much smaller than the smallest of those present before annealing. The differences in nucleation mechanisms of the grain-boundary glass phase will obviously lead to differing structures at the grain boundary. The relationship of these grain boundary structures to mechanical properties has been investigated and will be presented in subsequent publications.

\section{Summary}

It has been shown that applying a student $t$ treatment to multiple-spectra analyses includes all sources of error, as well as significantly enhancing the sensitivity of EDS analyses. It is then possible to reliably measure small differences in low-atomicnumber element content of fine-grained ceramics such as silicon nitride. The $\mathrm{Al}$ content of small grains in glass-containing samples is lower than that of large grains, indicating that the equilibrium concentration of $\mathrm{Al}$ in silicon nitride decreases during the precipitation process. This difference is not observed in annealed samples.

Accurate measurement of Al gradients within the $\beta$ grains of the garnet and cordierite-sialon systems indicates a difference in sec- ondary crystallization mechanisms. In the former system, the secondary silicon nitride nucleates on existing grains, whereas in the latter it nucleates among the cordierite. The glass-forming region of the cordierite- $\mathrm{Si}_{3} \mathrm{~N}_{4}-\beta_{30}$ diagram has also been presented.

\section{APPENDIX}

The sensitivity of EDS analysis improves as the number of spectra analyzed from similar areas increases. The error is described as follows:

$$
\text { relative error }=\frac{\mathrm{t}_{95}^{n-1} S}{\sqrt{n} X}
$$

where $n$ is the number of spectra analyzed, $X$ is the mean composition, $S$ is the standard deviation and $t$ is the Student $t$ coefficient which decreases with increasing $n .^{12}$

This formulation assumes that the standard deviation of the individual peaks is constant in various spectra (i.e., peak intensity, peak width, and deviation in the reference peak remain constant). When this is not the case, a pooled deviation should be calculated according to the relation

$$
S_{p}=\sqrt{\frac{\sum_{i=1}^{J}\left(n_{i}-1\right) S_{i}^{2}}{\sum_{i=1}^{j}\left(n_{i}\right)}}
$$

where $n_{i}$ is the number of counts in the $i^{\text {th }}$ peak and $S_{i}$ is the standard deviation of the $i^{\text {th }}$ peak The pooled deviation is calculated for the $\mathrm{Al}$ peaks from 20 spectra and this value is substituted in $\mathrm{Eq}$. $(\mathrm{A}-1)$. The procedure is then repeated for each peak, $\mathrm{Si}$, $\mathrm{Mg}$, etc.

\section{References}

${ }^{1}$ K. H. Jack, "The Significance of Structure and Phase Equilibria in the Devel opment of Silicon and SiAlON Ceramics," Sci. Ceram., 11, 125-42 (1981).

${ }^{2}$ M. H. Lewis, A. R. Bhatti, R. J. Lumby, and B. North, "The Microstructure of Sintered SiAlON Ceramics," J. Mater. Sci., 15, 103-13 (1980).

${ }^{3}$ T. M. Shaw, G. Thomas, and R. E. Loeman, "Formation and Microstructure of Mg-Si-O-N Glasses," J. Am. Ceram. Soc., 67 [10] 643-47 (1984).

${ }_{4}^{4}$. J. Headley and R. E. Loeman, "Crystallization of a Glass-Ceramic by Epitaxial Growth," J. Am. Ceram. Soc., 67 [9] 620-25 (1984).

${ }^{5}$ D. R. Clarke, N. J. Zaluzec, and R. W. Carpenter, "The Intergranular Phase in Hot-Pressed Silicon Nitride: II, Evidence for Phase Separation and Crystallization," J. Am. Ceram. Soc., 64 [10] 608-11 (1981).

"J. I. Goldstein, "Principles of Thin Film X-Ray Microanalysis"; pp. 83-120 in Introduction to Analytical Electron Microscopy. Edited by J. J. Hren, J. I. Goldstein, and D.C. Jay. Plenum Press, New York, 1979.

${ }^{7}$ D. B. Williams, Practical Analytical Microscopy in Material Science; pp. 55-90. Phillips Electronic Instruments, Electron Optics Publishing Group, Mahwah, NJ, 1984.

${ }^{8}$ K. H. Jack, "The Relationship of Phase Diagrams to Research and Development of SiAlONs"; pp. 241-85 in Phase Diagrams: Materials Science and Technology. Edited by F. L. Filey. Academic Press, New York, 1978

${ }^{9}$ L. J. Gauckler, J. Weiss, T. Y. Tien, and G. Petzow "Insolubility of $\mathrm{Mg}$ in $\mathrm{Si}_{3} \mathrm{~N}_{4}$ in the System Al-Mg-Si-O-N," J. Am. Ceram. Soc., 61 [9] 397-98 (1978)

${ }^{10}$ I. K. Naik, L. J. Gauckler, and T. Y. Tien, "Solid-Liquid Equilibria in the System $\mathrm{Si}_{3} \mathrm{~N}_{4}-\mathrm{AlN}_{-} \mathrm{SiO}_{2}-\mathrm{Al}_{2} \mathrm{O}_{3}$," J. Am. Ceram. Soc., 61 [7-8] 332-35 (1978).

"Steve Nunn, H. Hohnke, L. J. Gauckler, and T. Y. Tien, "Subsolidus Phase Relationships in Part of the System Si, Al, Mg/N,O," Am. Ceram. Soc. Bull. 57 [3] 320 (1978). T. Y. Tien, G. Petzow, L. J. Gauckler, and J. Weiss "Phase Equilibrium Studies in $\mathrm{Si}_{3} \mathrm{~N}_{4}$-Metal Oxides Systems"; pp. 89-99 in Progress in Nitrogen Ceramics. Edited by R. F. Riley. Mattinus Nijhoff, Boston, MA, 1983.

${ }^{12}$ E. Rothman and W. Ericson, Statistics - Methods and Applications. Kendail/ Hunt, Dubuque, IA, 1983 